did not then or subsequently present any scarlatinal eymptoms.

To make assurance doubly sure, I thought it would be Interesting to take the temperatures of the remalning 299 children. On August 23rd and on each of the two or three following days thls was carefully done, and much to my surprise, although these chlldren appeared to be in thelr usual health, no less than 131 had temperaiures of 99. and npwards, and 29 of this number hid temperatures betreen $100^{\circ}$ and $101^{\circ}$. In sll cases this slight pyrexla had disappeared within two or three days, and in no single instance was there subsequently any symptom of scarlatlns or peeling, though the children were kept under spesial observation. It was ascertalne 3 that out of the 131 chlldren, 23 had a history of a previous attack of scarlatin ?. No further cases occurred during this or the following zear.

On September 19th, twenty.geven days after the first taking of temperatures, as a control experlment I had the temperatures of all the children taken again, and they were all then found to be normal with the exception of three, the probable cauge of the slight pyrexia in these cases being respectlvely tuberculous glands, an ordinary cold, and a bllious attack. It cannot be often that opportunities present themselves for taklng temperatures on such a large s sale when a community is exposed to the Infection of a zpmotic disease; if any similar observatlons have been recorjed they have escaped my notlce. Thls pyrextal condition of a large group of children c jincldent with the possibility, if not the probabillty, of their inhallng the micrococel of scarlatins may be interesting enough to place on record. It may be fairly asgumed that it was more than a coincldence that 131 out of 299 chlldren should all be suffering from a slight elevation of temperature, though it is, of courae, possible that in some instances the small excitement of having the $t$ mperatures taken may have sent up the thermometer to a moderate extent, although this did not occur in a slngle instance in the subsequent control experiment. On neither occasion was there any catarrhal or other allment running through the school. It is difficult to resist the inference that most of these ahlldren had recelved a dose of the scarlatinal pol zon, bu lhat their powers of resistance were suffici ntl g great to prevent the occurrence of any of the usual eymptoms except the moderate amount of pyrexia. Whether the daily disinfection of the mouth and fuces with the perchloride solution modified or Inhibited the action of the scarlatinal viras is a matter of opinlon. My own experlence 0 i this and on other occasions leads me to belleve that an active disinfectant such 881 in 2,000 perchloride solution has an undoubtedly useful effect, and with ordinary care it can be safely need as a prophylactlc in a disease like scarlating where it is probable that the micrococcl find their entrance to the system from the faucial mucous membrane. It is, of course, a common experlence to limit an outbreak of scarlatina in a school to one or two cases without any other precantion than prompt isolation.

The experiences above related tend to suggest that In a community infected with scarlatins, in addition to those who show definite symptoms of the disesse, there are others who are affected by the polson to a minor extent as shown simply by an elevation of temperature; and it may be a neelal precantion to take the temperature of contacts, with the view of keeplng under special observa. tion those who though apparently quits well are suffering from a mojerate degree of pyrexis.

\section{NOTE ON THE TREATMENT OF EXPERI-}

\section{MENTAL TRYPANOSOMIASIS.}

BY ALDO CA STELLANI, M.D.,

DIRECTOR OF THE CLINIC FOR TROPICAL DISEASES, COLOMBO, CEYLON.

\section{Mercury Perchloride.}

IN 1903 Low and myselt while in Uganda treated forr cases of sleeplng slckaess with intravenous injectlons of mercury perchloride solution, applying in this way to sleeplng sickness the method of trestment devised by $B$ wccelli for varlous forms of septicaemla. In our report ${ }^{2}$ we

Reports of the Royal Society Bleeping Sickness Commission, No. 5 , stated that the intravenous injection of perchloride caused constantly a fall in the temperature, and this conditlon persisted for several days. The Improvement was not lasting in any of the four patients, and the disease ran its fatal course.

The remarkable fall in the temperature after the sublimate Injections has, however, always remained impressed on my mind, and at varlous times I have in Ceylon made experiments with the object of seelng whether mercuxy had any influence in experimental trypanosomisais; as the results were not very striking I did not publish them. In Ceylon sleeping sickness does not occur, and having been unsble to import animals experimentally inoculated with Trypanosoma gambiense I have made my experiments on monkeys, which I have inoculated with a trypanosome derived from a bullock of Indian breed. The try panosome Is probably a strain of $T$. evansi, though it is much less virulent then the typlcal $T$. evxnsi. All the inosulated monkeys develop a fever of remittent type and polyadenitls; death takes place after several months. The monkeys I have used for my experiments are of the genus Macacus and Cercopithecus. The solntion of perchloride used is according to Baccelli's formula:

$$
\begin{aligned}
& \begin{array}{lllll}
\text { Mercury perchloride } & \ldots & \ldots & 0.10 \mathrm{gram}
\end{array} \\
& \begin{array}{lllll}
\text { Sodium cnloride } & \ldots . & \ldots & \ldots & 0 \\
\text { Sterile water ... } & \ldots & \ldots & \ldots & 100 \text { c.cm. }
\end{array}
\end{aligned}
$$

Half c.cm. or $1 \mathrm{ccm}$. of this solution was Injected daily Intravenously. It is to be noted that in the monkeys I have used the superficial veins are not clearly visible, and it is necessary in most cases to make a small cut in the skin and partly dissect the veln chosen for Inoculation.

Without entering into the particulars of the investigation I may say that mercury perchloride given intravenously caused, almost constantsy, the temperature to fall to normal for a certain period of time; In some cases the enlarged glands became smaller; the trypanosome, however, never disappeared completely from the general circulation and the improvement was not maintained:

Quinine Cacodylate.

In 1906 it occurred to me to try the action of quinine cacodylate in experimental trypanosomissis. I had at that time under observation an obscure case of low intermittent fever of six months' duration; the patient, apart from the tever and a very slight enlargement of a few superficial lymphatic glands, did not show anything abnormal on physical examination; the liver and spleen were not enlarged. Tae case had been variously dirgnosed as malaria, paratyphold, Malta fever, syphilitic fever, beginning pseudo-leuksemia, trypanosomiasis, kala-azar latent tuberculosjs. The microscoplcal and bacteriological examination of the blood, urine, and faeces never gave any clue by which to form a definite diagnosis. The patient had been drenched with quinine, mercury, and liquor argenic 3lis. Although I was unable to make a definite dlagnosls, I tried emplrically injections of quinine cacodylate. Thirty such injections $(0.20 \mathrm{gram}$ esch injection) were sufficient to bring the temperature to normal, and the patient is at the present time enjoying perfect heslth. I then tried the same trestment in a typical case of kala-azar I had in the clinic; the improvement alter forty injectlons was remarkable; the patient, however, feeling so much better, left the clinic to go to $\mathrm{hls}$ distant village, and I cannot therefore say whether the Improvement was maintained. It is worth noting that the drug gave me fairly good results also in yaws.

Experiments have been carried out on monkeys inoculated with the same strain of trypanosome as those on which the mercury treatment was trled. The drug was given by subcutaneous injections ( 0.10 gram per injection) once or twice dally. The monkeys stood the drug well I may asy briefly that the drag shows a well-marked tryp anocide action for this particular strain of trypanosome. Alter 15 to 25 injectlons the trypanosomes are no longer present in the peripheral circalation nor in the enlarged lymphatic glands; the fever dieappears. In a certain percentage of cases, however, about 30 per cent., recurrences take place; when this bappens, quinine cacodylate given in large doses seems to have much weaker actlon than in the first attack.

Combined Treatment.

Ehrlich demonstrated that trypanosomes may become partially or totally immune to a given drug, and he 
emphasized the utility of combined treatments for irg $^{-}$ panosomiasis, as, for Instance, atoryl and trypanroth. Soon after Moore, Nlerensteln, and Tudd published the results of their important inveatlgations on the treatment of experlmental trypanosomiasls by various combined treatments. They atste that Thomas and Brelnl's atoxpl treatment was not sufficient to prevent recurrences in a number of cases, and from thelr experiments on $T$. brunci they came to the conclusion that Thomas and Brelnl's treatment thould be followed by a mercury treatment. According to them atoxyl acts on the ordinary adult stage of the trypanosome as found in the peripheral circulation, but not on the developmental forms of the parasite, which are not seen in the general circulation.

The comblned treatment I have trled is quinine cacodylate and mercury perchloride. The experiments were made on monkeys inocalated with the same strain of trypanosome as those on which the quinine cacodylate alone and the mercury treatments had been trled.

Three monkeys were treated with quinine cacodylate ( 0.10 gram per injection) and perchlorlde of mercury $(0005$ gram per intravenous injection), contemporarlly ; that is to say, they received one Injection of cacodylate in the morning and the mercury in the evening. The treatment lasted forty days. Three other monkeys recelved quinine cacodylate for twenty days and then perchlorlde of mercury for twenty more days. Three more monkeys received a dally Intravenous injection of perchloride of mercury for twenty days, and for twenty days more a dally subcutaneous injection (010 gram) of qulnine cacodylate.

The treatment, therefore, lasted In all the three groups of monkeys forty days. The trypanosome disappeared from the general circulation about the same time in the first two groups (between the fifteenth and nineteenth day); in the monkeys of the third group the trypanosome did not disappear completely during the mercury treatment; it disappeared between the twenty.second and thirtleth day.

At the present time, two months alter the comblned treatments were discontinued, the monkess of the first and second groups are apparently free from the trypano. some; as regerd the third group, a recurrence has taken place in one cf the mojkeys, though the trypanosome is present 11 verg small numbers.

\section{Conchusions.}

1. Quinine cacodylate shows a well.marked trypanocide action in monkeys experimentally inoculated with a strain of trypanosome closely resembling $T$; evainsi.

2. Mercary perchloride improves the general condition of the Inoculated monkeys, and frequently causes the temperature to subside to normal. Glven alone, however, its trypanoclde action is not very marked. In patlents affected with sleeping sickness, it would seem from the experiments made by Low and myself In 1903 that mercury perchlorlde given by Intravenous injection induces a fall in the temperature, bat the improvement lo only temporary.

3 . I suggest that quinine cacodylate alone, or, better, in combination with Intravenoug injectlons of perchloride of mercury, should be tried in sleeping sickness, using large doses. If it should be found that quinine cacodglave has a marked trypanoclde action also on $T$. gambiense, the advantage of this drug over other preparations would be its powerful action on the malaria parasites. This would be an appreclable advantage, as in the experience of many observers, among whom Low and myself, a large number of sleeplng sickness patients are suffering also from chronic malaria.

4. Qulnine cacodylate besides its trypanoclde propertles and its action on Laveran's parasites, has apparently some action on otber protozoa, as, in my experlence, its use is beneficial in kala-azar and yaws.

\section{BIBLIOGRAPHY}

Bojce: The Treatment of Sleeping 8ickness. British MEdicat JodrnaL, Beptember 14th. 1907

Ehrlich : Chemotherapeutische Trypanosomen Studien. Berl. klin.

Woch. 1907 Nos. 8-12.
Low and Castellani: Report on Sleeping Sickness from its Clinical Aspects. Royal Society's Sleeping Sickness Commission Report,

Manson: Tropical Diseases. 1907

Moore, Nierenstein and Todd: Ann of Trop. Med. 1907

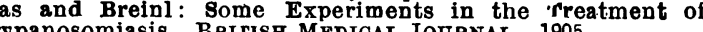

\section{AN UNUSUAL DEFORMITY OF THE FOOT. BY BASIL KILVINGTON, M.S., M.D.MELB,} VICTORIA.

THk following abnormality of both feet recently came under my notice, and its rarity and blological int irest make the case worth reporting.

It occurred in a boy, aged 12 years, who consulted me for some minor atlment. There was nothing like it in the family record, as far as the parents could remember, and the family history was unimportent.

The abnormality consisted in an ex. tremely short first metatarsal bone, the head not reaching within an inch of that of the second metatarsal.

When a young child the great.toe projected ellghtly inwards away from the foot, but now; probably from long

wearing of a boot. it lies parallel with the others.

The sklagram, taken by Mr. Fryett, shows the bones of the foot, the condition being bllateral. There is little power of abduction, but addactlon of the toe is unusually powerlul, though it cannot be brought in apposition with the outer members

The absence of the usual support given by the head of the first metatarsal causes the boy to bear most of hls weight on the outer side of the loot, and the parents volunteered the statement that his boots always wore out on this side. He is not so active in running and walking go hls brothers.

There is a marked flexion of the first pholanx at the metatarao-phalangeal joint, so that on standing the head of the phelanx is touching the ground. Thls explaing the apparently very short length o! that phalanx in the sklagram, as it is taken almost end on. Actually the bone is of normal aize. I regard this flexion at the joint as a secondary occurrence, the object being to allow part of the bodyweight to be transmitted to the ground through the first phalanx.

It is obvious that the disabllity does not lend itself to treatment, but the interest lles in the fact that it closely resembles the condition normally present in the anthropoid apes. In them the foot is a grasplng organ, and the big toe is somewhat like the thumb, being shorter than the other toes and apposable.

The great toe is still apposable in the human fetus, and is much more movable in childhood than in adult life.

The resemblance to the skeleton of the ape would be still closer if the great toe did not lie parallel with the 